\title{
Transformative learning in nursing students through a service learning project with a vulnerable community
}

\author{
Amanda S. Eymard, Pamela Breaux, Kimberly Dozar \\ Nicholls State University, Thibodaux, LA, USA
}

Correspondence: Amanda Eymard. Address: Nicholls State University, P.O. Box 2143, Thibodaux, LA, 70310. Email: Amanda.eymard@nicholls.edu.

Received: July 1, 2012

Accepted: September 18, 2012

Online Published: November 8, 2012

DOI : 10.5430/jnep.v3n3p35

URL: http://dx.doi.org/10.5430/jnep.v3n3p35

\begin{abstract}
Transformative learning is the phrase used by the authors to describe nursing students' learning that occurred during a service learning project. Nursing faculty and nursing students visited a population of impoverished children in an after school program and provided education regarding health promotion and injury prevention. Students designed teaching plans regarding topics identified in a needs assessment: (1) injury prevention related to safety, (2) nutrition, (3) physical fitness, (4) health, and (5) bullying. A qualitative analysis of student journals was completed. The students viewed themselves as change agents, and reflected on their stereotypes, and prejudices regarding children living in poverty, and caring for this population.
\end{abstract}

\section{Key words}

Service learning, Nursing, Children, Poverty, Students, Transformative learning

\section{I ntroduction}

Alarming numbers of families live in poverty or below poverty levels in the United States. According to the U. S. Census Bureau $^{[1]}$, in 2009 , the official poverty rate was $14.3 \%$. More specifically, the poverty rate in Louisiana is $19.2 \%$, the second highest rate in the nation and the highest in the South ${ }^{[2]}$. Certain families lack the support and security to provide the essentials to their children. If these children grow up without interventions, they are at an increased risk for poor health, injury, and even death ${ }^{[3]}$. The combination of a high rate of children living in poverty and well documented risks associated with this population of children prompted the following service learning project.

Nursing faculty conducted a needs assessment for children living in poverty near the university and designed a service-learning project for pediatric nursing students based on the needs of the community. The goal of the project was to teach this vulnerable population of children about health promotion and injury prevention. The purpose of the project was for the nursing students to gain knowledge of specific needs of diverse populations and experience in teaching. An additional purpose of the project was to raise the students' awareness of the need for community service in hopes that the students will continue to participate in community service activities throughout their nursing careers. 


\subsection{Literature review}

Although it is disheartening and difficult to imagine even one child living in poverty, it is even more difficult to hear the alarming numbers associated with children living in poverty across the United States (U.S.). Millions of children are living in or below poverty levels in the U.S. ${ }^{[1]}$. Low-income children are disproportionately at a disadvantage for poor health outcomes during childhood ${ }^{[4]}$. Children living in poverty often live in low opportunity neighborhoods and are at a higher risk of poor health outcomes based on community characteristics such as housing and neighborhood safety. According to Johnson, Dickinson, Mandic, and Willis ${ }^{[5]}$, “community matters because the spatial and social contexts in which children develop physically, socially, and emotionally can have profound effects on children’s health” (p.153). The need for health promotion and injury prevention education among children living in poverty was identified throughout the literature review. Several health disparities identified for low-income and minority children included accidental injury, excessive weight gain, and obesity ${ }^{[3,5]}$. All of these health disparities have the potential to impact the children's health, growth, and development.

In the United States, accidental injury accounts for $60 \%$ of childhood deaths between the ages of 1 and 21, and each year 20 million children sustain an injury that leads them to seek medical attention ${ }^{[6]}$. According to Newgard et al ${ }^{[7]}$, injury occurs more in populations of lower income, lower education, and more non-white residents. The five leading causes of child injury were identified as (1) road traffic injuries, (2) drowning, (3) poisonings, (4) burns, and (5) falls. Harvey ${ }^{[8]}$ points out that education, along with skills development, and behavioral change programs for children and parents should be one important strategy at reducing child injury.

Additional health disparities identified for children living in poverty include excessive weight gain and obesity ${ }^{[3,5]}$. Obesity among children and adolescents is a growing problem in the United States. More specifically poor and minority children are disproportionally affected. Among adolescent black girls, the rate of obesity is $24 \%$ compared with $15 \%$ of non-Hispanic white girls ${ }^{[5]}$. Hudson ${ }^{[9]}$ found that more than $75 \%$ of black children ages $2-5$ years old with a body mass index (BMI) of greater than 95\% do not eat the recommended servings of fruits and vegetables each day. Financial and environmental factors greatly contribute to these obesity outcomes. Parents on a fixed budget may not be able to afford fresh fruits and vegetables. Diets of children living in poverty typically consist of more high-calorie, low-nutrient foods. Low-income children live in neighborhoods with more fast-food restaurants and fewer supermarkets. Lack of adequate physical activity is also a contributing factor to weight gain and obesity of children living in poverty. For example, environmental factors such as fewer playgrounds and a lack of neighborhood safety also contribute to obesity outcomes. Parents' perceptions of neighborhood safety affect the amount of time spent outside; therefore more time is spent indoors with video games and television ${ }^{[5]}$.

Addition identified risk related to children and their development is bullying. Bullying is defined as the act of inflicting verbal, emotional, or physical abuse upon others ${ }^{[6]}$. Bullying is on the increase during the school-age years. Bullied children are reportedly lonely and isolated, while those children who participate in bullying are reported to have low self-esteem, poor grades, and poor socialization skills ${ }^{[6]}$. Proper education regarding prevention of bullying is imperative for school age children. According to Jensen and Dieterich ${ }^{[10]}$, bullying-prevention programs provided to school age children may be effective in decreasing aggression and violence in this population.

An important aspect in nursing education is the opportunity of nursing students to work with vulnerable populations. The American Association of Colleges of Nursing (AACN) ${ }^{[11]}$ stated compassionate and patient-centered care of diverse populations requires knowledge and sensitivity to variables such as culture, socioeconomic status, and health disparities. According to the AACN ${ }^{[11]}$, working with marginalized and vulnerable populations is a critical component of nursing education. Service learning is a pedagogical approach to providing care to vulnerable populations as well as educating nursing students ${ }^{[12]}$. Service learning promotes an outreach partnership with a particular community and an academic group ${ }^{[13]}$. Experience in service learning activities allows the students to reflect on services provided and broadens the students' sense of civic responsibility ${ }^{[13]}$. According to Vogt et al ${ }^{[13]}$, service learning has consistently demonstrated 
positive increases in students' knowledge and skills related to community awareness, poverty, health care equity, and social justice. Service learning offers "promise to foster social change and produce graduates who are fully engaged citizens and professionals” (p.1) ${ }^{[12]}$.

\subsection{Project overview}

\subsubsection{Students and activity}

Over two semesters, forty-two junior level baccalaureate nursing students participated in this service learning activity as part of their clinical requirements for a pediatric nursing course. Faculty members collaborated with representatives from an after school program for underprivileged children living in poverty in the local area. The after school program requested nursing students to join the after school program and teach children on various topics focusing on health promotion and disease prevention. Faculty members of the pediatric nursing course decided this was an excellent opportunity to expose nursing students to diverse populations and participate in service learning. The service learning experience provided an opportunity for pediatric nursing students to apply the didactic knowledge in a clinical setting.

The students were initially assigned a topic and asked to provide a teaching plan to present to children ranging in age from 4-18 in an after school program. A rubric designed by the faculty for the teaching plan was provided to the students. Topics included injury prevention related to safety, nutrition, physical fitness, health, and bullying (see Table 1). Students worked together in groups to formulate age-appropriate objectives and teaching strategies. After the teaching plans were approved by the faculty members, each group of students was given one hour to present their teaching plan to the children.

Table 1. Topics presented to children during service learning project with description and teaching strategies included for each topic.

\begin{tabular}{|c|c|c|}
\hline Topic & Description & Teaching Strategies \\
\hline Safety & $\begin{array}{l}\text { Fire } \\
\text { Water } \\
\text { Stranger } \\
\text { Home } \\
\text { Bike } \\
\text { Car } \\
\text { Pedestrian }\end{array}$ & $\begin{array}{l}\text { Posters } \\
\text { Role Play } \\
\text { Discussion } \\
\text { Handouts } \\
\text { Games }\end{array}$ \\
\hline Nutrition & $\begin{array}{l}\text { Diet } \\
\text { Obesity }\end{array}$ & $\begin{array}{l}\text { Handouts } \\
\text { Posters } \\
\text { Games }\end{array}$ \\
\hline Health & $\begin{array}{l}\text { Puberty } \\
\text { Body Changes } \\
\text { Hygiene } \\
\text { Hand washing } \\
\text { Body Image }\end{array}$ & $\begin{array}{l}\text { Lecture } \\
\text { Discussion } \\
\text { Demonstration } \\
\text { Games }\end{array}$ \\
\hline Physical Fitness & $\begin{array}{l}\text { Sports } \\
\text { Play } \\
\text { Structured exercise }\end{array}$ & $\begin{array}{l}\text { Games } \\
\text { Demonstration }\end{array}$ \\
\hline Bullying & $\begin{array}{l}\text { Physical } \\
\text { Verbal } \\
\text { Emotional } \\
\text { Cyber } \\
\text { How to be a good friend }\end{array}$ & $\begin{array}{l}\text { Demonstration } \\
\text { Role Play }\end{array}$ \\
\hline
\end{tabular}

Teaching strategies included games, visual aids, exercise activities, handouts, discussions, and role playing (see Table 1). Students took ownership of their topic and designed their teaching activities specific to their assigned topic. Allowing the 
nursing students flexibility with teaching strategies encouraged creativity and fostered leadership skills. Over the two semesters, several groups of nursing students visited the children and presented their teaching plans. As the project progressed, new teaching needs were identified and addressed in the project.

\subsubsection{Community}

The community was an area of low income, government assisted housing, which consisted of primarily African American families in Louisiana. Within this community was an established after school program that focused on tutoring and life skills. Children enrolled in this program ranged from ages 4 to 18.

\subsubsection{Debriefing}

Upon completion of the presentations the group met to debrief about the experience. Faculty realized the importance of meeting with students to discuss the students' feelings and experiences. According to Gillis and MacLellan ${ }^{[12]}$, debriefing with students after each service learning experience is necessary to allow students to process the experience. Service learning experiences can be emotional for students due in part to working with a vulnerable population ${ }^{\text {[12] }}$. Faculty members were prepared to offer support and guidance to students during the debriefings. No specific guidelines or framework was used for the debriefing sessions. During the debriefing sessions, surprisingly, the students expressed their thoughts on the execution of their teaching plan rather than their feelings regarding the overall experience. The expectation was for students to express their feelings and emotions regarding the service learning project. This did not occur until students began journaling about their experiences.

\subsubsection{J ournaling}

It is imperative that service learning activities include a reflective process for the students. This self-reflection by the students can take many possible formats, such as journaling or focus groups ${ }^{[13]}$. Journaling was required as part of this service learning experience. Students were required to write about their thoughts and feelings prior to beginning the project, upon completion of their teaching plan, and completion of the service learning project. No specific framework was used to guide student reflections. They were only asked to write in their journals at the three designated times during the project. A qualitative study of student journal entries was conducted by the three participating faculty members at the completion of the service learning project. Students gave the faculty members permission to use quotes and information from their journals for the following research study.

\section{Method/ Data analysis}

A qualitative research study was conducted with student journals as the source of data. Students were required to journal throughout the duration of the project. Data analysis was performed using a content analysis approach ${ }^{[14]}$. Individually, three faculty members analyzed the student journals manually line by line using across-case comparisons ${ }^{[14]}$. Student journals were coded to identify themes within and between the journal entries. Prior to initiation of the project, approval from the university's Institutional Review Board (IRB) was received.

\section{Results}

Codes were assigned to two broad categories: (1) student nurses, and (2) children. The first broad category was specific to journal entries regarding the student nurses. The second broad category was specific to journal entries regarding the children involved in the service learning project. An algorithm (see Figure 1) depicts the two broad overarching categories identified. The algorithm further displays particular themes shared by the nursing students and the children which were identified throughout data analysis. The identified themes result in an overarching theme of "connecting to others.” Then, at an even higher, more abstract level, the algorithm displays how "connecting to others" results in a deeper learning in the 
nursing students in the affective domain, which results in a change, which the authors are referring to as "transformative learning."

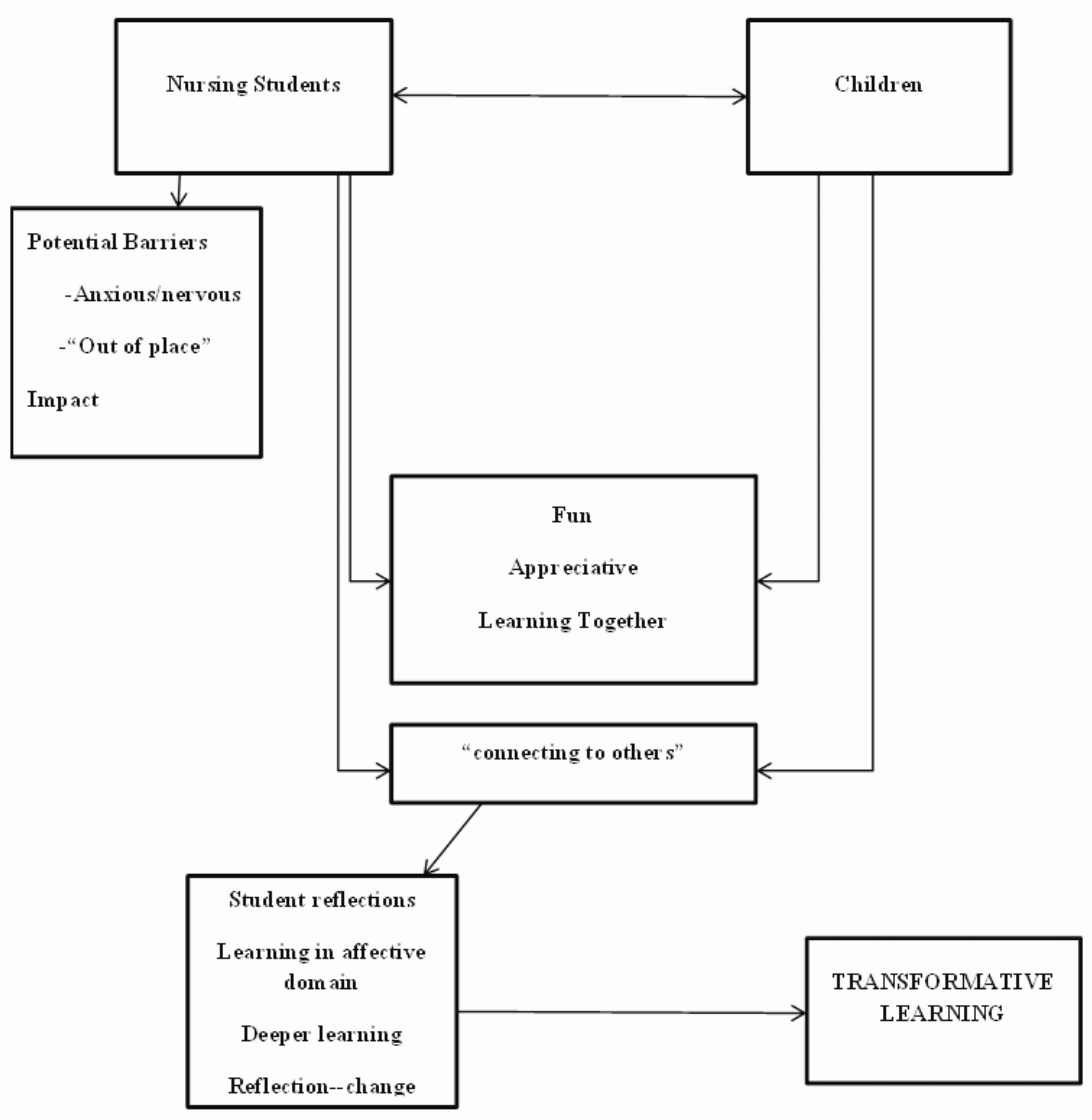

Figure 1. Algorithm of development of transformative learning

\section{Student nurses}

Within the two broad categories of codes, 27 codes were identified throughout the data consistently regarding the student nurse participants. These 27 codes were then developed into two major themes regarding the student nurses. According to Munhall ${ }^{[14]}$, qualitative research is "interested in the subjective experience and perception of the person". The two emergent themes from the student journal data exemplified the students' experiences and perceptions: (1) potential barriers, which consist of nervous/anxious and "out of place," and (2) make a difference/impact.

\section{Potential barriers}

Nervous/anxious. In their journals, students consistently expressed a feeling of nervousness or anxiety when initially beginning the project. Students frequently wrote about a feeling of anxiety when preparing their teaching materials and then again consistently prior to visiting the service learning location. Frequently, students mentioned their anxiety again when they expressed a sense of relief stating their anxiety had decreased considerably after meeting and interacting with the children during the project. One student wrote, "I felt a little nervous, because it's something I have never done before.”

Out of place. Overwhelmingly, the location of the service learning project was referenced in nearly all student journals. The service learning project was conducted in the neighborhood of a government housing development. Words used by students in their journals to reference the location included, "government housing," "projects," "ghetto," and a "bad area." 
Students expressed a feeling of "being out of place" and "unhappy about location." One student described the area as being "associated with crime and drugs." Another reported the area as "scary and dangerous."

According to Gillis and Mac Lellan ${ }^{[12]}$, students often express strong emotions regarding what they saw, heard, or personally experienced. Through reflective journaling, students often come to recognize their perceptions, assumptions, and stereotypes concerning vulnerable individuals who may have had different life experiences than their own. While many of the students initially expressed uneasiness concerning the location, many of them expressed gratitude for the experience. One student wrote, "I grew up knowing that this is where the blacks live and one can die by going in there." Another student wrote, "This project made me take a step back to realize how blessed I was to grow up in an area that I did and have all my needs fulfilled without a doubt.”

\section{Make a difference/ impact}

Students consistently wrote in their journals expressing a desire to make a difference or an actual feeling of making a difference or an impact in the children's lives. According to Gillis and Mac Lellan ${ }^{[12]}$, service learning provides an opportunity for nursing education to adopt an orientation to social justice. This allows students to realize they can be active in contributing to meaningful social change among vulnerable populations. As students focus their reflections upon their experiences and put their thoughts into words, they are empowered and feel they are able to impact change and serve as change agents ${ }^{[12]}$.

Codes included within this theme regarding students include: (1) pride, (2) confidence, (3) comfortable, (4) rewarding, and (5) success. A student wrote, "I hope that I touched someone in there to let them know that you might not have the best life, but you can make it best for yourself with determination and faith." Another student wrote, "I hope I can leave an impact on their lives that will help them make healthier decisions leading to a healthier life."

\section{Children}

Within the two broad categories of codes, 16 codes were identified throughout the data consistently regarding the participants who were all children. These 16 codes were then developed into three major themes regarding the children. These three major themes were also identified in the nursing student categories as major themes. Therefore, these three major themes are presented in the algorithm as being shared by the nursing students and the children. Munhall ${ }^{[14]}$ states “embracing another's subjectivity is the critical activity for compassionate nursing practice”. During this project, students observed and interacted with the children. Observational research puts the researcher in the context that is of interest ${ }^{[15]}$. Three emergent themes from the student journal data exemplified the students' observations and perceptions regarding the children and their experiences during the service learning project: (1) having fun, (2) learning together, and (3) being appreciative.

\section{Having fun}

In their journals, students consistently described the children as having fun or enjoying themselves. Students used very descriptive words, such as laughing, giggling, smiling, and glowing. Excerpts from student journals demonstrating the theme of fun among the children include, "I can see the glow and excitement in their eyes," and "I was shocked to see how much fun we all had.”

\section{Learning together}

Throughout the journals, students consistently described the children as learning and participating in the activities. Many student journals expressed amazement regarding the children's eagerness to participate during the project. Examples of student journal entries depicting the theme of participating or learning by the children and students were identified throughout the journal entries. One student wrote, "The children answered all of our questions. I was very surprised to see 
how much the children interacted with us.” Another student wrote, "They were listening very attentively. They had many comments and lots of input."

\section{Being appreciative}

Student journals consistently noted an observation from nursing students regarding the children as being appreciative to the students. Examples of student journal entries depicting the theme of the children as appreciative include, "These children seem to be very thrilled and appreciative for us going and spending time with them" and "The children were very loving and accepting of us and took pride in giving us the right answers.”

\section{Connecting to others}

As the two major concepts were further analyzed, an apparent overarching theme of "connecting to others" was identified by the researchers. A sense of connectedness was identified throughout the many journal entries. The nursing students and children connected to one another during the service learning project. They connected through the fun experience where they learned together. It is this connectedness that allowed the students to move into learning in the affective domain. The students were able to achieve a deeper level of learning through reflection. Students reflected on their own personal life experiences as a result of interacting with the children.

\section{Student reflections}

At an even higher, more abstract level, the algorithm (see Figure 1) displays how "connecting to others" resulted in a deeper learning in the nursing students in the affective domain through self-reflection. Several students reflected on their own personal experiences during the project. They wrote about being able to process their emotions and reflect on their life experiences. The students were able to share their fears, emotions, and memories through journaling. This process was quite cathartic for the students and demonstrated authenticity to the nursing faculty. The students were able to look within themselves and reflect on their life experiences and relate the experiences to the service learning project. The topics discussed in student self-disclosure journal entries include (1) obesity, (2) "raised in the projects," (3) bullying, and (4) puberty.

One group of students were assigned to teach children about obesity and healthy eating habits. Students shared a fear of being judged by the children due to their weight. They vividly described a feeling of extreme uneasiness concerning their weight and having to teach about obesity. One student wrote, "It's scary to think about what the group might think about learning about nutrition and exercise from someone who is obviously obese and who may not be practicing what they are preaching." Another student wrote, "I fear the questions that may come at me about my weight and how I will answer them.”

Through journaling, a student shared and reflected on her own experiences with living in government assisted housing as a child. The student expressed a feeling of comfort in returning to a familiar environment. Empathy is evident in the student's journal entries. The student shared her own personal experiences and a feeling of being able to relate to the children because of these previous experiences. This student demonstrates the importance of cultural diversity among health care providers and the significance of meeting a client where they are and accepting them without judgment. The student reflected on her experiences with people visiting her as a child and wrote, "I remember becoming very excited just to meet new faces and to know that there were people outside of the projects who were actually concerned about where I may end up in life.”

Another group of students was assigned to teach the children about bullying and while it often occurs, it is not appropriate and should be prevented and/or reported if it occurs. One student self-disclosed through journaling how she was bullied as a child and how she reflected on her personal experiences with bullying to impact the children. The journal entries demonstrate a passion for prevention of bullying. One student reflected on her own experiences with bullying and wrote, "I think everyone has been a victim of bullying at some time in their lives. I was bullied until fourth grade because I was born 
deaf.” The students were able to share with one another about their own experiences with bullying and one student wrote, "Everyone in my group has been a victim of bullying, so it was easy for us all to relate."

Finally, one group of students was assigned to teach children about puberty and expected body changes during this developmental phase. One student shared and reflected on her own experiences with puberty through journal entries. The student demonstrated heartfelt difficulties with her own developmental process and a desire to assist the children with this process by providing appropriate information. The student wrote, "I fought with puberty with no advice from siblings or my parents. Therefore, I relied on TV, magazines, and friends, which is probably why I battled with major insecurity issues."

\section{Transformative learning}

The authors are proposing this service learning project resulted in a change in the nursing students, which the authors are referring to as "transformative learning". According to Mezirow ${ }^{[16]}$, transformative learning is a route to critical thinking. It is a much higher level of learning when compared to uncritical assimilation of knowledge. Mezirow ${ }^{[17]}$ states adult learners learn best by making meaning of their experiences. The students who participated in this project were able to connect with their experiences during the service learning project and "make meaning" of their experiences. A noticeable change or transformation was noted in the nursing students who participated in the service learning project. This transformation is the final, highest level theme represented in the algorithm (see Figure 1).

\section{Conclusion}

Limitations of this study include the lack of using a framework or model to guide reflections of students. Also, a framework was not used by the researchers for the debriefing sessions with the students. Utilizing frameworks for both of these activities would have further strengthened the study by offering cues to access the depth and breadth of student learning through experiences in the service learning projects. Cues offer a systematic way of reflecting on experience and the use of cues helps students to internalize a way of inquiring over time ${ }^{[18]}$. Including the frameworks could have possibly facilitated deeper learning in the students.

This service learning project has provided new data regarding nursing students' perceptions and experiences regarding observing and interacting with a population of vulnerable children living in poverty. The junior level baccalaureate nursing students were able to interact with a population of vulnerable children in the children's living environment. Through this project, a better understanding of how to interact with and teach children was gained by the students. Valuable prevention and health promotion information was disseminated to the children. But the most evident and far reaching impact of this project was the profound effect the project had on the nursing students.

The nursing students were able to reflect on their own personal prejudices, stereotypes, perceptions, admitted misperceptions, and life experiences and relate these to the service learning project. The students consistently commented regarding making an impact or difference on the children without fully realizing the tremendous impact or difference the project had on them individually. This change in the students, termed transformational learning, was realized by the faculty during content analysis of their journals. One student stated, "I left with the feeling that I have changed one life for the better-even if not through me, but through my group. I can honestly say, I think that we made a positive impact on their lives. I feel so proud of my group, my class, and my school.” According to Vogt et al. ${ }^{[13]}$, literature consistently reveals positive increases in student knowledge and skills related to social justice, community awareness, and poverty with students often commenting about the "life-changing" aspect of service learning projects. The nursing students of this service learning project were able to look within themselves as health care providers, advocates, change agents, and most importantly, caring individuals, and reflect on their perceptions, stereotypes, and prejudices regarding children, poverty, children living in poverty, and caring for this population. The faculty members plan to continue offering service learning projects in the community setting. 
Implications for nursing education include the importance of continuing to include service learning projects in nursing curriculums. Additionally, students should be provided with opportunities to interact with a diverse population throughout their educational experiences. This service learning project highlights the importance of teaching in the affective domain by allowing students to reflect on their feelings and perceptions throughout the learning activity.

\section{References}

[1] U.S. Census Bureau [Interent]. 2011. Available from: http://census.gov.

[2] HopeNetworks. 2011. Available from: http:// hopenetworks.org/poverty.htm.

[3] Hernandez, V., Montana, S., Clarke, K. Child health inequality: Framing a social work response. Health \& Social Work. 2010; 35(4): 291-301. PMid:21171536 http://dx.doi.org/10.1093/hsw/35.4.291

[4] Power, C., \& Kuh, D. Life course development of unequal health. In J. Siegrist \& M. Marmot (Eds), Social inequalities in Health. 2006; 27-54. New York: Oxford University Press. PMid:16452651 http://dx.doi.org/10.1093/acprof:oso/9780198568162.003.0002

[5] Johnson, S., Dickinson, K., Gomez Mandic, C., \& Willis, E. Community matters for children’s health. Pediatric Annals. 2011; 40(3): 152-159. PMid:21417206

[6] Ricci, S. \& Kyle, T. Maternity and pediatric nursing. Philadelphia: Lippincott, Williams \& Wilkins. 2009.

[7] Newgard, C., Schmicker, R., Sopko, G., Andrusiek, D., Bialkowski, W., Minei, J., et al. Trauma in the neighborhood: A geospatial analysis and assessment of social determinants of major injury in North America. American Journal of Public Health. 2011; 101(4): 669-677. http://dx.doi.org/10.2105/AJPH.2010.300063.

[8] Harvey, A., Towner, E., Peden, M., Soori, H., \& Bartolomeos, K. Injury prevention and the attainment of child and adolescent health. Bull World Health Organization. 2009; 87: 390-394. http://dx.doi.org/10.2471/BLT.08.059808.

[9] Hudson, C. Being overweight and obese: Black children ages 2-5 years. The ABNF Journal. 2008; 89-91. PMid:18717206

[10] Jensen, J., Dieterich, W. Effects of a skills-based prevention program on bullying and bully victimization among elementary school children. Prevention Science. 2007; 8: 285-296. PMid:17968657 http://dx.doi.org/10.1007/s11121-007-0076-3

[11] American Association of Colleges of Nursing (AACN). Media-Fact Sheet [Internet]. 2010. Available from: http://www.aacn.nche.edu?Media/FactSheets.htm. Accessed September 15, 2010.

[12] Gillis, A., \& Mac Lellan, M. Service learning with vulnerable populations: Review of the literature. International Journal of nursing Education Scholarship. 2010; 7(1): 1-27. PMid:21126228 http://dx.doi.org/10.2202/1548-923X.2041

[13] Vogt, M., Chavez, R., \& Schaffner, B. Baccalaureate nursing student experiences at a camp for children with diabetes: The impact of a service-learning model. Pediatric Nursing. 2011; 37(2): 69-73. PMid:21661605

[14] Munhall, P. L. (Ed.). Nursing research: A qualitative perspective. (4th Ed.). Boston: Jones \& Bartlett Publishers. 2007.

[15] Willis, J. Foundations of Qualitative Research: Interpretive and Critical Approaches. Thousand Oaks, CA: Sage Publications. 2007.

[16] Mezirow, J. Transformative learning: Theory to practice. New Directions for Adult and Continuing Education. $1997 ;$ 74: 5-12. http://dx.doi.org/10.1002/ace.7401

[17] Mezirow, J. Critical theory of adult learning and education. Adult Education Quarterly. 1981; 32(1): 3-24. http://dx.doi.org/10.1177/074171368103200101.

[18] Johns, C. Engaging reflection in practice. A narrative approach. 2006. 